\title{
Implications of design deficiency on building maintenance at post-occupational stage
}

Received (in revised form): 9th February, 2007

\section{Sr Nor Haniza Ishak}

is a building surveyor, lecturer and post-graduate supervisor in the Faculty of the Built Environment, University of Malaya, Kuala Lumpur, Malaysia.

\section{Afaq Hyder Chohan}

is a lecturer in the Department of Architecture, Mehran University of Engineering \& Technology, Jamshoro, Pakistan. Currently, he is a post-graduate student in MSc in Building Science, University of Malaya, Faculty of the Built Environment, Kuala Lumpur, Malaysia.

\section{Ahmad Ramly}

is a professor and postgraduate supervisor in the Faculty of the Built Environment, University of Malaya, Kuala Lumpur, Malaysia.

Correspondence: Sr Nor Haniza Ishak, Faculty of the Built Environment, University of Malaya, 50603 Kuala Lumpur, Malaysia; Tel: +6037967 6813; Fax: +6037967 5713; E-mail: niza_alambina@um.edu.my

\begin{abstract}
The repercussions from design failures have been the subject of much study. With every passing moment the implications of design deficiency presents a new set of actions and reactions. In this contemporary technological/scientific era, this field of study acts as a 'Testing Lab' of designers' ideas. Any part of the globe can serve as a testing field for such studies if there is building design. These studies can help both the designer to improve their skills and industry to develop new materials. Despite current technological advancement, the prevention of unplanned building maintenance is still not being achieved. This research paper highlights examples of design that were not finished within the required parameters and thus resulted in faults. The study also highlights the effect of faulty design on building maintenance.
\end{abstract}

Journal of Building Appraisal (2007) 3, 115-124. doi:10.1057/palgrave.jba.2950061

\section{Keywords:}

design deficiency, unplanned maintenance, design decisions, faulty design and building maintenance

\section{INTRODUCTION}

$$
\text { 'To fail to plan is to plan to fail.' - Wood (2003) }
$$

The essence of all result-oriented work may be identified in this quotation. In the context of design one can adapt this phrase to, 'if a designer fails to plan well the plan will turn out badly'. The theme of this study is to highlight the examples of design failure to plan well. In understanding the theme one can use a law of physics as a metaphor. Newton's third law of force is 'For every action there is a reaction'. For designers/architects this law could be interpreted as 'for every design decision/consideration (action) there is a 
consequence (reaction)'. As such this research tries to explore the actions of design and the consequence of their actions.

Building maintenance is becoming an increasingly important field of study and it is even more important in developing countries. Since developing countries often have an ineffective organisational setup and a high demand for housing, the cost of building maintenance can have a significant detrimental effect on future development. These factors are also responsible for worsening the condition of existing buildings to the point where existing finance and management facilities are stretched beyond their capabilities. Housing constitutes a valuable asset for all income groups and for the majority of the world population but in underdeveloped countries good quality housing is a rarity. Thus, housing in these locations requires adequate and effective maintenance to avoid cumulative decay and deterioration, which will result in health concern and affect the productivity of the occupants. The lack of maintenance often results in deterioration that leads the building to the point of collapse or to it having to be demolished. The question arises as to whether there is any way to avoid this waste of the built environment in developing countries.

The answer lies in better design as the lack of it would appear to be a major cause of the problem. Hence, it could be suggested that unplanned maintenance can be avoided if building design takes account of the need for careful and methodical planning, budgeting, monitoring and execution.

\section{REPERCUSSIONS OF DESIGN DEFICIENCY}

Faults in building design place a heavy burden on the building for rest of its life and there is no compensation for it. In such situations, the responsibility falls on the shoulders of the designer in that they must think carefully with full concentration and consideration towards completion of their design project.

Explaining the link between maintenance and building design, Ramly (2006) suggests that four sectors of building design should be considered and regarded as important if one is to avoid the need for unplanned maintenance at the post-occupation stage. These sectors are:

- the main fabric which includes walls, floors, roofs, doors and windows;

- internal finishes which includes ceiling and wall finishes as well as floors;

- special design features such as decorative elements for the doors, windows, glass, air vents and special brick and stone work;

- the fourth and the last sector is cleaning and house keeping of all building components.

The study identified deterioration in these sectors that resulted from design faults, which subsequently imposed a heavy financial burden on the occupier or owner.

Based on the outline of causes derived from the work of Gibson (1979), the implication of design fault on maintenance in buildings has resulted from the following:

- the consequence of thermal movement;

- the consequence of inefficient detailing;

- the consequence of improper material selection; and

- the consequence of poor design for access for maintenance measures.

The designer must understand what consequences the use of materials in combination can impose on their designs. Thermal movement in materials can affect a building in a number 
of ways. It can cause cracking in walls or plaster and fractures in structural elements if consideration has not been given to thermal expansion. Thermal movement can also result in distortion of otherwise impervious joints with the result that penetration of water takes place or there is a loss of adhesion. Inadequate detailing can cause deterioration of the building façade. In the absence of proper architectural detailing of rainwater discharge from the building face, water may penetrate into the building or stagnate within or on the construction. Ponding water is a potential source of disease, as it can harbour insects that transmit malaria or dengue fever, for example. Incorrect material selection can add to the financial burden of maintenance, as well as be the cause of thermal movement, distortion, ponding, or early failure. Whereas poor access for maintenance will cause delay in the repair process that escalates the cost and increases the probability of substandard remedial actions.

Nicastro (1997) reported the case of a high rise luxury condominium in Austin, Texas, USA and built in 1980 in which 'the fine network of the cracks hinted at widespread cladding cracks'. The identified defect was described by the author as like 'skin cancer' due to the uncontrollable situation of maintenance. The solution under such condition is usually total replacement of the building's cladding. This study also shows that even in the wealthy parts of the world, poor material selection and design control can still result in expensive defects in their buildings.

\section{Materials}

Designers often select different materials for the façade of a building in order to create interest, visual depth and contrast. But a range of materials will need careful design if the junctions of these materials are not to cause a need for early remedial work. Cook and Hinks (1992) state that the use of a range of materials for the external envelope of a building can lead to differences in absorption pattern. The different levels of absorption of each material will affect the surface and cause concentration of water run off with different pattern and staining on the façade. The use of such ideas clearly indicates that improper material selection and lack of knowledge regarding their physical properties will affect future building maintenance as shown in Figure 1. In addition, the author also suggests that insufficient detailing of projections and other water protecting building elements will result in surface decay and deterioration of reinforcements leading to the need for early and expensive maintenance intervention.

Contractors usually do not bother to use the leftover materials from other remedial works, even if they were undertaken relatively recently, but they do use out-of-date materials in the construction. This has an affect on future building maintenance and may have an affect on the health of the building workers. An example of this type of mistake is

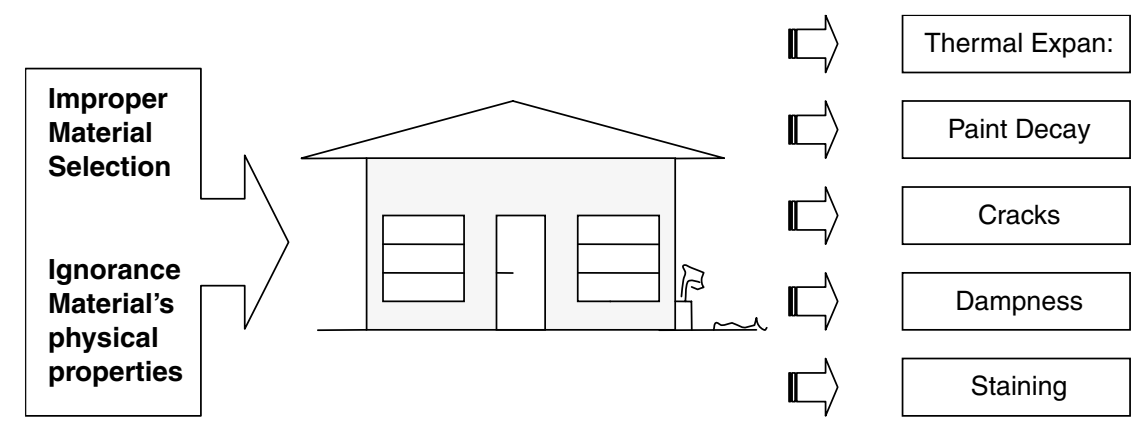

Figure I: The implication of building material's physical properties towards maintenance 
given by Nicastro (1997) in a building where the sealant used was out-of-date. The sealant lost its flexibility in critical parts of the building, which affected its ability to act as water proofing. This can cause fungal growth and lead to gaps occurring due to thermal expansion. The author also highlighted masonry defects stating 'the 24 storey tower was constructed in 1983 and shortly after completion suffered severe distress in exterior brick masonry'. There may be several reasons for the defects in the masonry at postoccupational stage but the design stage was not sufficient to prevent the defects occurring. This defect also was influenced by shrinkage, column shortening and creep. A number of tall residential buildings experienced similar problem with their lift shafts, exterior cladding and other continuous elements such as City Mall, Karachi, Pakistan, Angkasa Vista, Kuala Lumpur and Champaka Apartments, Kalang, Kuala Lumpur.

\section{Ventilation}

Poor ventilation design in buildings can be well understood in the context of human morphology. Ventilation components in buildings such as windows, exhausts and ventilation ducts and air passages, serve as the respiratory organs and passages for buildings. But in the case of substandard design, these ventilation channels require more maintenance also if they are not to affect the health of the residents (Figure 2). Sobotka and Thriene (1996) shows that poor ventilation can cause mould and fungi even in new buildings and which has significant implications on health. The study reveals that exhaust shafts were not properly designed and in many cases kitchens and bathrooms were not provided with windows and the lack of air movement resulted in the shafts being lined internally with thick mould. It shows that poor ventilation allows fungi to grow, and because of the lack of provision for maintenance access in the design the shafts were never cleaned.

\section{Wet areas}

Wet areas in a building are always vulnerable to deterioration and decay and require more attention and maintenance. The implication of their failure is so severe that it can even cause partial collapse. Water seepage in these wet areas is likely to cause major defects if they arise at the post-occupational stage. Seepage results mainly from poor design, poor construction and the use of substandard materials, while poor workmanship and the deterioration of building materials are the root cause of dampness within walls (Beukel, 1996). As the saying goes 'prevention is better than cure' and this should be remembered whenever the designer and construction team set out to create wet areas of a building. The finished works should have water tight plumbing, drainage systems and water proofing membranes and the materials used should be capable of resisting any chemicals that may be applied or spilt on the floor. Ensuring that this work has achieved the correct standard

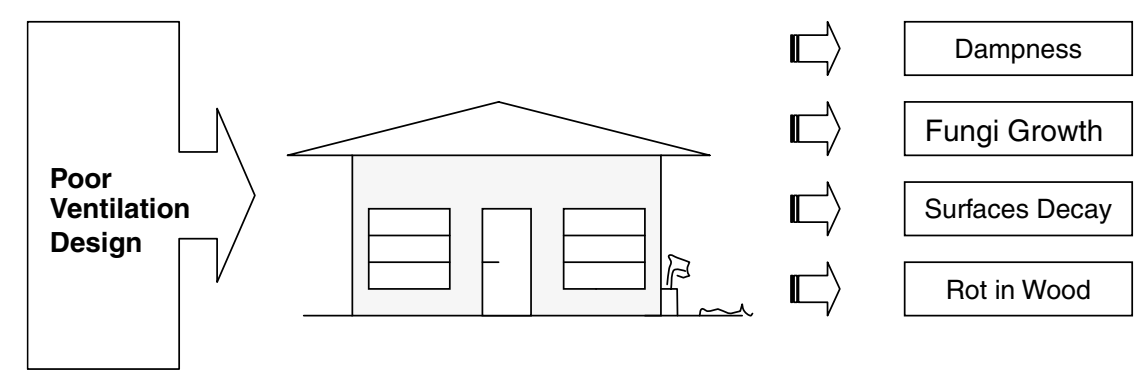

Figure 2: The impact of poor ventilation design 
after it is constructed is, however, a very difficult task, which is why it is so important that the work is designed and constructed so that it will prevent future problems, but this is not always achieved.

Ghasson (2003) conducted a study in Birmingham, UK on housing stock of high rise apartment buildings which revealed several aspects of building maintenance caused by design faults and which have resulted in condensation and leaking roofs, and mould growth caused by poor ventilation. Poor insulation and defective sealants have lead to subsequent problem of moisture penetration and water logging. This study showed that a number of defects that arise in residential buildings are because of design faults. He, however, concluded that these types of defect are common in social housing and are not restricted to the buildings being studied.

\section{Floors}

Floors are also subject to developing defects that lead to a need for maintenance at the post-occupational stage if the correct design and materials have not been specified as part of the design (Figure 3). According to Cook and Hinks (1992), curling of concrete and cracking of screeds are common defects arising because of incorrect concrete mixing and inadequate curing time. But it is evident that both defects are related to different stages of the design process. The nature of these defects indicates three aspects of design fault that affect the cost of future maintenance. First, the lack of a precise specification for the concrete mixes; secondly, the use of an inexperienced work force and thirdly, inefficient and inadequate supervision.

\section{Building lifespan}

Describing the interrelation of design and the life cycle of a building, Wood (2003) states that the life of the building is an important factor and is often little considered at the briefing stage. He illustrates the absence of this interrelationship by way of examples taken from many high-density residential towers designed in 1960 that failed because of both social and structural problems. A building that has had to have major repairs or has demolished early in its expected life is always associated with faulty design. The concept of life expectancy is, however, also tied in with the quality and extent of maintenance that is carried out. A well-maintained building can be expected to have a good life span provided that the design has not imposed excessive maintenance costs. Therefore, upon developing the correlation between the expected lifespan, design and maintenance of a building, one can conclude that design faults can shorten the lifespan of a building.

The word 'life' has been used by several researchers searching for a better understanding of the built form. It is interesting to note that through this approach the researchers have intentionally (or unintentionally) considered a building as a human
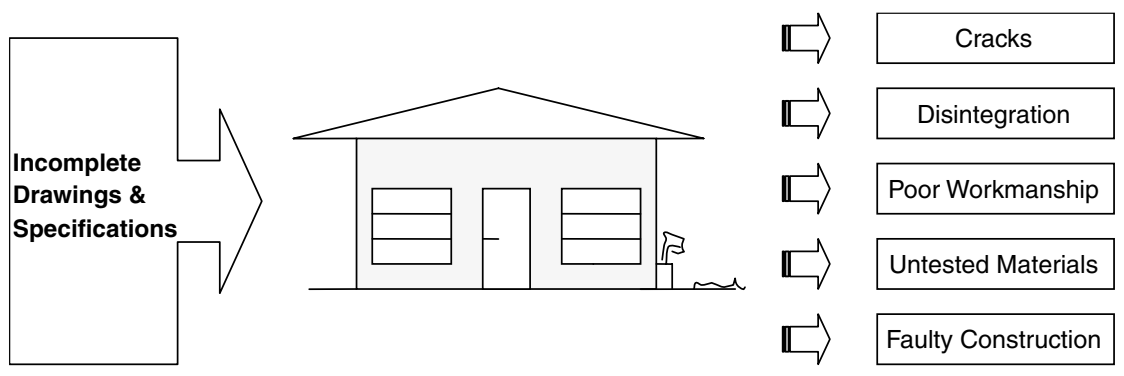

Figure 3: The development of building defects due to incomplete drawing \& specifications 
metaphor because the word 'life' is a characteristic of human beings. There are several defects that appear in buildings at the post-occupational stage, which are similar to human ailments. For example, cracks in a building are similar to untreated wounds that not only cause distress through their appearance but also can contribute to contamination occurring in the body, which if left untreated may cause partial damage or the need for amputation. Cracks in buildings may have similar consequences for the building. Highlighting the harmful impacts of cracks, Seeley (1987) adds that 'cracks in a building normally results from failure or defective construction and are almost invariably unsightly and unacceptable to occupants. If severe they may result in loss of stability'. Therefore, it can be concluded that cracks in a building are the result of design faults and can cause partial or total collapse.

To avoid the implication of design faults on the need for future maintenance, constant research and close observation of existing methods of design and construction practice are needed. In addition, it requires more international forums to address and exchange the issues and experiences seen in different parts of world. In Singapore, an analysis of defects in wet areas of buildings by Chew (2005) reported faults in design, the construction phase and material selection. The main sources of defects were the mistakes made at the design stage, construction phase, maintenance practice and in materials selection. The defects that resulted from these failures included tile debonding, mastic failure, the staining of tiles, cracking, water leakage through cracks, water leakage where pipes passed through walls, paint defects, water ponding, spalling of concrete and unevenness of tile surface and poor pointing. This long list of defects is only those found in the wet areas of buildings which constitute only a small part of the total building. This alarming amount of design faults also creates an opportunity for similar research in other parts of the building as well.

Al-Hammad et al. (1997) identified the improper selection of finishing material as being a contributory cause for high maintenance costs in the post-occupational stage of the building. Examples that are quoted included painting buildings with dark colours in a dusty area where they required a lot of cleaning and absorbed heat and also using paints that cannot survive in the climate and humidity to which the building is subjected. The weather and environmental conditions caused deterioration because the design of the façade did not specify suitable types of colour and finish for the building's exterior. The result is a need for more maintenance than should have been the case had proper consideration been given in the design (Figure 1).

The design of the building façade can also cause maintenance problems if the designer does not consider the requirements for access if effective maintenance is to be carried out during the lifetime of the building. For example, the cleaning of a building's exterior surface, windows or changing lamp bulbs in high locations.

Thus, it can be concluded that building designers are not always aware of the extent of maintenance required for the building's elements and do not make available maintenance equipment to enable these routine tasks to be carried out. This shortcoming of design has implications for future maintenance and the cost of that process.

It is fair to mention that faulty design is not restricted to any one country. But its existence is felt more wherever there is a trend for introducing new materials and technology in construction. It is essential that new techniques and materials should be suitable for the location in which they are used. Therefore, there is a need for newly introduced materials and technology to be tested in different regions and under variety of usage.

A study in England conducted by Olubodun (2000) on housing stock reveals the similar nature of problems in the housing stock under study. The survey revealed that various implicating factors of design faults and construction are present in housing of 
United Kingdom. These defects are attributed to faults of design, construction, supervision and workmanship. Examples were:

- Rising dampness affecting both exterior and interior surfaces contributing to cladding/ plaster decay on external wall surfaces.

- Condensation on floors may increase the relative humidity and temperature variation along with surface deterioration of floor finish. In case of wooden floor, this may cause rot in wood.

- Poor supervision and workmanship has resulted in poor flow in waste pipes and has caused back flow problem in the waste and drainage system.

- Roof and floor failure are also mentioned as being the consequence of inferior workmanship and poor design.

Apart from the direct influence of the design consideration on building maintenance, there are also several other hidden factors that have the tendency or potency to influence the design of building and create the need for extensive maintenance in the building at postoccupational stage. One such factor is the communication gap. Communication in design can be explained as the verbal and written discharge of the ideas during design stage or corrective ideas during the construction phase. This involves large numbers of people in the design, construction supervision and management of the building. Three parties are essential to an effective outcome: the designer, contractor/construction manager and owner. A gap will, however, occur if this team does not communicate their needs and expectations to the other.

Masterman (2002) states that poor construction also results from the traditional approach to construction that separates design and construction. The author presents the picture of the ongoing practice in the fields of design and construction where there is a failure to synchronise the design activities and construction phase. But a sound link between design and construction is essential if one is not to follow a path to future faults. Since design is an activity that is to be considered and tailored according to the need of the individuals, it requires close coordination from different parts of the design team. In such circumstances, the contractor and other building trade professionals are not always aware of the requirements of the design or the intention of the designer. Thus, there is a need to develop a working relationship between designer and construction team. Failure of such obligations also causes poor construction and leads to a need for unforeseen postoccupational maintenance or repair.

'Poor construction' is a broad term and it is associated with a number of faults, for example tile fixing, plastering, formwork, plumbing and flooring. Therefore, it can be concluded that in order to avoid all such construction fault which can cause high future maintenance cost at a later stage, it is necessary to revise the traditional mode of procuring building construction by developing a correlation between designer and construction professionals.

A dedicated designer aims to achieve a distinctive design that may act as a trendsetter in the design world. In the course of such activities, the designer often runs over budget that results in cost cutting later in the project that leads to unacceptable design solutions when viewed from the cost of maintaining the building over its lifespan. Griffith and Sidwell (1995) refers to inconsiderate designs that affect the building design and influences the construction phase in the form of costly/uneconomic construction which often leads to incomplete projects and improper material selection by unauthorised personnel. Conceivably the author is directing towards the condition which can cause the 
design faults that are likely to implicate the cost of future maintenance, for example improper material selection as described previously. Hence, it can be suggested that a designer should judge the realities of their design very closely and try to present a design that is more closely related with the demands of the client and its ultimate user to minimise the undue intervention of other professionals.

\section{ULTIMATE IMPLICATIONS OF DESIGN DEFICIENCY}

This section describes cases where fatal incidents have resulted from faulty design and construction. Most relate to large-scale problems in the developed world, for example United States, France and Japan. Building faults are not just a problem in emerging world countries, but those are the countries that can least afford the high costs of design faults in the high cost of and need for future maintenance. Important lessons can be learned from such incidents where certain unexpected circumstances as well as poor design occur together to cause serious building collapses.

\section{Case study 1: The collapse of terminal 3, Dubai International Airport}

Eight people were killed and others injured after part of a terminal under construction at Terminal 3 Dubai International Airport collapsed on 27th September, 2004. During the preparation of a wall, a section of the reinforcement cage fell, trapping workers. The terminal was designed by French architect Paul Andreu who also designed Terminal 2E at Paris' Charles de Gaulle International Airport that also had part of the structure collapse (see below).

\section{Case study 2: The collapse of terminal 2E at Paris Charles de Gaulle Airport}

On 23rd May, 2004 sections of the roof of Paris Charles de Gaulle Airport's new terminal $2 \mathrm{E}$ fell onto a boarding footway. The passage in turn collapsed onto airport service vehicles parked underneath resulting in four deaths. In February 2005, the results from the administrative inquiry were published and experts pointed out that there was no single fault, but rather a number of causes for the collapse, in a design that had little margins of safety. According to them, the concrete vaulted roof was not resilient enough and had been pierced by metallic pillars, and some openings weakened the structure. Sources close to the enquiry also disclosed that the whole building chain had worked as close to the limits as possible, so as to reduce costs. Designer Paul Andreu denounced the building companies for having not correctly prepared the reinforced concrete.

\section{Case study 3: The sinking of Kansai Airport, Japan}

According to report of Sims (2001), in 1994 Kansai International Airport, Japan was opened with great fanfare and it is widely regarded as an engineering marvel. It is situated on 1,300-acre artificial island in Osaka, Japan's second largest city and was the first largescale airport built on reclaimed land. Seven years after completion, however, the airport started to sink and since its construction began in 1987 it has subsided by 38 feet. The airport complex consists of a runway, air terminal, train station, shopping mall and hotel. The airport operator of the Kansai International Airport Company has already spent about $\$ 2.21$ bn on repairs and includes building a concrete wall in the terminal's basement to guard against seawater seepage. The sinking of Kansai has raised doubts in Japan and abroad about the safety and maintenance of Kansai International. This report questions whether the world's most expensive airport was worth that price? 


\section{Case study 4: The collapse of Highland Towers, Kuala Lumpur}

In 1993 the collapse of Highland Towers in Kuala Lumpur, Malaysia resulted in 48 deaths. According to the report on incident (Maverick, 2006), one of the major causes was improper soil testing. The peripheral conditions of site resulted in undermining. The failure of retaining walls under heavy rains was a contributing factor, causing a landslide that led to the building's collapse. There were two types of design errors, improper soils bearing test and pre construction site visit at pre-design phase and the failure to identify the peripheral condition at site, together with the failure to design an inadequate retaining wall to contain the site and the building that stood on it.

\section{Case study 5: Florida high-rise collapse}

The failure of the formwork of the One Bal Harbour development in Miami Beach Florida during construction in May 2006 resulted in the deaths of three construction workers. Gresko (2006) reported that the partial collapse resulted from the failures of the formwork while quick drying concrete was being poured. The workers were on the 27 th level of the building pouring a concrete roof when the formwork below them failed and dropped them to the 26th floor. This condominium building had passed all inspections of Bal Harbour's building department. The failure was attributed to the quality and stability of formwork. The accuracy of formwork is important for the future performance of the concrete structure of a building, and errors in its dimensions, set out or structure may have serious implications for the future performance of the building.

\section{CONCLUSION}

While a journey of thousand miles begins with a single step, the most complex design of a building starts from the single stroke of designer. Errors in design can, however, result in unplanned maintenance where the designer fails to understand the buildability of that initial concept. The designer who is aware of the risk is more likely to create buildings that will require only planned maintenance. One way of evaluating the work of the designer is to go through the occupier's experience of maintenance requirements, even if the building may be regarded as a landmark of urban design.

Thus, it can be suggested that there must be a strong relationship between design and maintenance and only those design should be considered good which were proved as less demanding in terms of maintenance. This research has revealed several important factors at various design stages. The work has aided understanding of avoidable building/housing maintenance issues caused by design faults. The consequence of poor design has been considered from the minimum level of maintenance such as surface decay to the ultimate level of collapse. Design faults not only result in unplanned maintenance they also are expensive in terms of the lives of occupants and the cost of repairs.

Faulty design and its consequences are a global problem that can be seen in both developed and underdeveloped countries. There is a need for more research to be conducted in this field to resolve the design deficiencies that result in a high maintenance and monetary burdens.

\section{References}

Al-Hammad, A., Assaf, S. and Al-Shihah, M. (1997) 'The effect of faulty design on building maintenance', Journal of Quality in Maintenance Engineering, 3(1), 29-39.

Beukel, A.V.D. (1996) 'Cost of defects, how to diminish', Proceedings of International Symposium on Building Defects, Verena.

Chew, M.Y.L. (2005) 'Defect analysis in wet areas of buildings', Construction and Building Materials, 19(3), 165-173. 
Cook, G. and Hinks, A.J. (1992) Appraising Building Defects, Longman Scientific Technical, London, UK.

Gresko, J. (2006) '3 Killed in Florida High-Rise Collapse', washingtonpost.com, The Associated Press, Last updated Saturday, 6th May, 2006.

Griffith, A. and Sidwell, A.C. (1995) Constructability in Building \& Engineering Projects, Palgrave Macmillan, Basingstoke, UK.

Ghasson, S. (2003) 'A low cost maintenance approach to high rise buildings', Journal of Facilities, 23, 315-322.

Gibson, E.J. (1979) Development in Building Maintenance-1, Applied Science Publisher Ltd, London.

Masterman, J. (2002) Introduction to Building Procurement Systems, Spon Press, London.

Maverick, S.M. (2006) 'Highland Tower Tragedy. Available at http://constructionrisk.blogspot.com/2006/02/ highland-tower-tragedy.html, accessed 8th February, 2007.

Nicastro, D.H. (1997) Failure Mechanisms in Building Construction, ASCE Press, Reston, VA.

Olubodun, F. (2000) 'A factor approach to the analysis of components' defects in housing stock', Structural Survey, 18(1), 46-58.

Ramly, A. (2006) 'A link between design and maintenance', Journal of Building Engineers, 81(5), May.

Seeley, I.H. (1987) Building Maintenance, Palgrave Macmillan, Basingstoke, UK.

Sims, C. (2001) 'Losses Mount at Kansai while the Airport Sinks', The New York Times.

Sobotka, A. and Thriene, B. (1996) 'Sanitary problem for living spaces and health risks involved', Toxicology Letters, 88, 365-368.

Wood, B. (2003) 'Approaching the care free building', Facilities, 21(3-4), 74-79. 